\title{
INFLUENCE OF COMPACTION ENERGY ON SOIL STABILIZED WITH CHEMICAL STABILIZER
}

\author{
Anjaneyappa ${ }^{1}$, Amarnath M.S ${ }^{2}$ \\ ${ }^{1}$ RASTA, Centre for Road Technology, Bangalore -58 \\ ${ }^{2}$ Department of Civil Engineering, Bangalore University, Bangalore -56 \\ anjaneyappa@hotmail.com,amaranth_ms@rediffmail.com
}

\begin{abstract}
Increase in traffic along with heavier magnitude of wheel loads cause rapid deterioration in pavements. There is a need to improve density, strength of soil subgrade and other pavement layers. In this study an attempt is made to improve the properties of locally available loamy soil using twin approaches viz., i) increasing the compaction of soil and ii) treating the soil with chemical stabilizer. Laboratory studies are carried out on both untreated and treated soil samples compacted by different compaction efforts. Studies show that increase in compaction effort results in increase in density of soil. However in soil treated with chemical stabilizer, rate of increase in density is not significant. The soil treated with chemical stabilizer exhibits improvement in both strength and performance properties.
\end{abstract}

Keywords: compaction, density, subgradestabilization, resilient modulus $* * *$

\section{INTRODUCTION}

The optimization of designs to make road infrastructure cost effective and ensuring sustainability, particularly in regard to consumption of large material resources is receiving increased impetus. The performance of pavements can be improved by improving the compaction of structural components and subgrade.Compaction constitutes an essential part of the number of other methods of soil improvement techniques like soil stabilization.Manyadditives are tried to improve the properties of soilsincluding traditional stabilizers viz., lime, cement, bitumen, etc. andnon traditional stabilizers in the form of industrial waste materials, chemical stabilizers.In addition to higher compaction effort,treating soil with suitable stabilizer may be a better alternative towards attaining a sustainable and stable pavement structure.Recently many patented new chemical stabilizers are accredited by Indian Roads Congress (IRC)for use in pavement layers.In this study a locally available loamy soil treated with one such accredited stabilizer is compacted to four different energy levels. Theunconfined compressive strength (UCS) and performance of stabilized soil are evaluated.

\section{LITERATURE REVIEW}

Rauch A Fet.al, (2003) performed compaction, swell potential and triaxialtests on clayey soils treated with commercial stabilizers. Samples were compacted to modified Proctor compaction and cured for 7 days. The authors concluded that there were individual cases of some marked improvement.
Santoni RL et.al,(2003) performed UCS tests on silty sand treated with 6 polymers. Samples were cured at $72 \mathrm{deg} F$ and $40 \%$ relative humidity for different curing period. The authors concluded that few polymers showed significant unconfined compressive strength improvement.

Perlindh (2004) indicates citing various studies by researchers that compaction of a stabilized soil is important to achieve a good quality and to obtain the desired service life of the stabilized material. Stabilization changes the compaction properties to give a material that needs more compaction energy compared to untreated soil to achieve the same dry density.Austoroads(2001) working group on road stabilization agreed that default compaction method was $100 \%$ standard compaction. Because i)Most of the documented research in Australia based on standard compaction of sample at $100 \%$ ii) no performance data bound stabilized materials had been presented showing either standard modified Proctor compaction has achieved a better performance in the field. Vorobieff(2006) concluded that the belief by some practioners that modified compaction of the samples will provide better performing bound stabilized pavement should be replaced with requirement for all research testing to be conducted at standard compaction.It may be inferred from literature that there is need to understand the strength and performance behaviour of soil treated with any new stabilizer compacted to different energy levels. 


\section{SOIL, STABILIZER AND COMPACTION}

\section{EFFORTS}

Locally available loamy soil was selected for studyinglaboratory compaction characteristics of soil treated with stabilizer at four different compaction efforts. The properties of soil used in the studies are presented in Table.1. 'Soil Fix' is a patented polymer liquid stabilizer is used for stabilization of soil.The stabilizer is accredited by IRC for use in pavement layers. The properties of stabilizer is presented in Table 2 . The soil was treated with $0.5,0.75$ and $1 \%$ dosage by weight of the soil. The compaction efforts adopted in the studies is presented in Table 3 .

Table 1 Properties of Soil

\begin{tabular}{|l|c|}
\hline \multicolumn{1}{|c|}{ Test } & Result \\
\hline Wet sieve analysis & 9 \\
\hline Gravel (\%) & 43 \\
\hline Sand (\%) & 48 \\
\hline Silt and Clay & 30 \\
\hline Atterberg limits & 19 \\
\hline Liquid limit (\%) & 11 \\
\hline Plastic limit (\%) & 19.15 \\
\hline Plasticity Index (\%) & 12.2 \\
\hline Compaction - IS heavy & 9 \\
\hline Max dry density ( kN/m ${ }^{3}$ ) & SC \\
\hline Optimum moisture content (\%) & \\
\hline CBR(\%) ( 4day soaked) & \\
\hline Soil Classification & \\
\hline
\end{tabular}

Table 2 Physical and Chemical Properties of Stabilizer

\begin{tabular}{|l|l|}
\hline Appearance & Milky Grey Liquid \\
\hline Odour & Slight \\
\hline PH & $8.0-9.0$ \\
\hline Boiling Point & approximately $100^{\circ} \mathrm{C}$ (as per water) \\
\hline Flammability & None \\
\hline Vapour Pressure & As per Water \\
\hline Specific Gravity & $>1.0$ \\
\hline Water Solubility & Fully miscible \\
\hline
\end{tabular}

Table 3 Laboratory Compaction Energy Levels

\begin{tabular}{|l|l|l|l|l|l|}
\hline $\begin{array}{l}\text { Compactio } \\
\mathrm{n} \\
\text { Energy } \\
\text { Level }\end{array}$ & $\begin{array}{l}\text { Weig } \\
\text { ht of } \\
\text { Ham } \\
\text { mer, } \\
(\mathrm{kg})\end{array}$ & $\begin{array}{l}\text { Heig } \\
\text { ht of } \\
\text { fall } \\
(\mathrm{m})\end{array}$ & $\begin{array}{l}\text { No of } \\
\text { blows }\end{array}$ & $\begin{array}{l}\text { No } \\
\text { of } \\
\text { lay } \\
\text { ers }\end{array}$ & $\begin{array}{l}\text { Energy } \\
\text { Level } \\
(\mathrm{kN}- \\
\left.\mathrm{m} / \mathrm{m}^{3}\right)\end{array}$ \\
\hline IS - light & 2.6 & 0.31 & 55 & 3 & 580 \\
\hline $\begin{array}{l}\text { Intermediat } \\
\text { e Energy } \\
\text { Level 2 } \\
\text { IEL-2) }\end{array}$ & 4.89 & 0.45 & 20 & 5 & 959 \\
\hline $\begin{array}{l}\text { Intermediat } \\
\text { e Energy } \\
\text { Level -1 } \\
\text { IEL -1) }\end{array}$ & 4.89 & 0.45 & 30 & 5 & 1439 \\
\hline \begin{tabular}{l} 
IS - heavy \\
\hline
\end{tabular} & 4.89 & 0.45 & 55 & 5 & 2638 \\
\hline
\end{tabular}

\section{PREPARATION AND CURING OF SPECIMENS}

\section{TREATED WITH STABILIZER}

The stabilizeris first added to water optimum moisture content (OMC) foundat respective compaction energy level and mixed thoroughly then added to pulverized soil. The soil and water polymer were then thoroughly mixed and samples were compacted to different compaction energy levels. The cylindrical specimens of $38 \mathrm{~mm}$ x $76 \mathrm{~mm}$ size are prepared for unconfined compression (UCS)and repeated load tests. The specimens were kept in oven at $50^{\circ} \mathrm{C}$ for 48 hours and then cured in sunlight for durations of 7,14 and 28 days. The curing method adopted is as per recommendation of stabilizer manufacturer.

\section{INFLUENCE OFSTABILIZER OMC, MDD AT VARIOUS COMPACTION EFFORTS}

The effect of stabilizer on OMC- Maximum Dry Density (MDD) values at different compaction energy levels is presented in Table 4.The increase in density with respect to increase in compaction energy is slightly higher for stabilised soil.The OMC increases with increase in stabilizer content. 
Table 4 Effect of Stabilizer on OMC MDD at Various Compaction Energy Levels

\begin{tabular}{|c|c|c|c|}
\hline Compaction Energy Level & Stabilizer $(\%)$ & OMC $(\%)$ & MDD $\left(\mathrm{KN} / \mathrm{m}^{3}\right)$ \\
\hline \multirow{4}{*}{ IS- Light } & 0 & 14.8 & 16.75 \\
\cline { 2 - 4 } & 0.5 & 15.0 & 16.7 \\
\cline { 2 - 4 } & 0.75 & 15.2 & 16.75 \\
\cline { 2 - 4 } & 1 & 15.2 & 16.9 \\
\hline \multirow{4}{*}{ IEL - } & 0 & 13.2 & 17.75 \\
\cline { 2 - 4 } & 0.5 & 13.6 & 17.80 \\
\cline { 2 - 4 } & 0.75 & 13.8 & 17.85 \\
\hline \multirow{4}{*}{ IEL - 1 } & 1 & 13.8 & 17.9 \\
\cline { 2 - 4 } & 0 & 12.8 & 17.80 \\
\cline { 2 - 4 } & 0.5 & 13.6 & 17.82 \\
\cline { 2 - 4 } & 0.75 & 13.8 & 17.9 \\
\hline \multirow{4}{*}{ IS- Heavy } & 1 & 13.8 & 17.9 \\
\cline { 2 - 4 } & 0 & 12.2 & 19.15 \\
\cline { 2 - 4 } & 0.5 & 12.2 & 19.20 \\
\cline { 2 - 4 } & 0.75 & 12.6 & 19.34 \\
\cline { 2 - 4 } & 1 & 13.0 & 19.4 \\
\hline
\end{tabular}

\section{STRENGTH AND PERFORMANCE}

The UCS tests were carried out on cured soil treated specimens with different dosages of stabilizer and results obtained are presented in Table 5.Repeated load tests were conducted onstabilized soil specimens compacted to different energy levels subjected to haversine load. The frequency and rest period adopted in the study are $1 \mathrm{~Hz}$ and 0.5 seconds respectively. The influence of number of repetitions on accumulated plastic strain for soil treated with $1 \%$ stabilizer at 0.8 stress ratio is presented in Fig.1. The resilient characteristics are compared between stabilized and unstabilized soils after 30000 load repetitions are presented in Fig. 2 and 3.

Table 5 Unconfined Strength Results

\begin{tabular}{|c|c|c|c|c|c|}
\hline \multirow{3}{*}{$\begin{array}{l}\text { Compaction } \\
\text { Energy Level }\end{array}$} & \multirow[t]{3}{*}{ Stabilizer (\%) } & \multicolumn{4}{|c|}{ UCS $(\mathrm{kPa})$} \\
\hline & & \multicolumn{4}{|c|}{ Curing Period ( days) } \\
\hline & & 0 & 7 & 14 & 28 \\
\hline \multirow{4}{*}{ IS- light } & 0 & 100 & - & - & - \\
\hline & 0.5 & - & - & 600 & 820 \\
\hline & 0.75 & - & - & 760 & 960 \\
\hline & 1.0 & - & - & 780 & 1240 \\
\hline \multirow{4}{*}{ IEL -2 } & 0 & 220 & - & - & - \\
\hline & 0.5 & - & 440 & 690 & 880 \\
\hline & 0.75 & - & 490 & 980 & 1200 \\
\hline & 1.0 & - & 580 & 1200 & 1490 \\
\hline \multirow{4}{*}{ IEL -1 } & 0 & 320 & - & - & - \\
\hline & 0.5 & - & - & 960 & 960 \\
\hline & 0.75 & - & - & 1120 & 1320 \\
\hline & 1.0 & - & - & 1360 & 1400 \\
\hline \multirow{4}{*}{ IS-Heavy } & 0 & 530 & - & - & - \\
\hline & 0.5 & - & 680 & 1040 & 1200 \\
\hline & 0.75 & - & 960 & 1180 & 1300 \\
\hline & 1.0 & - & 1320 & 1880 & 1800 \\
\hline
\end{tabular}




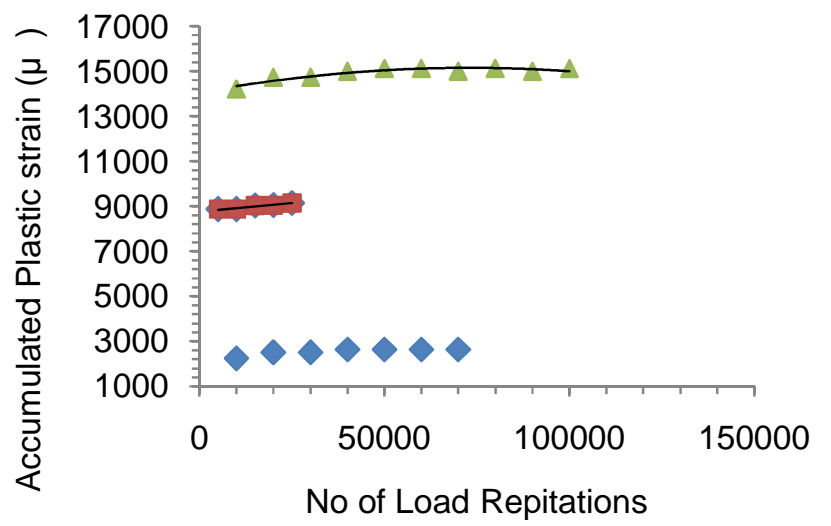

IS Light, 0.8 SR ( $656 \mathrm{kPa})$

- IEL -1, $0.8 \mathrm{SR},(768 \mathrm{kPa})$

$\triangle$ IS Heavy, 0.8 SR, (960 kPa)

Fig. 1 Relationship between Accumulated Plastic Strain and No of Repetitions for $1 \%$ Stabilizer at 0.8 Stress Ratio

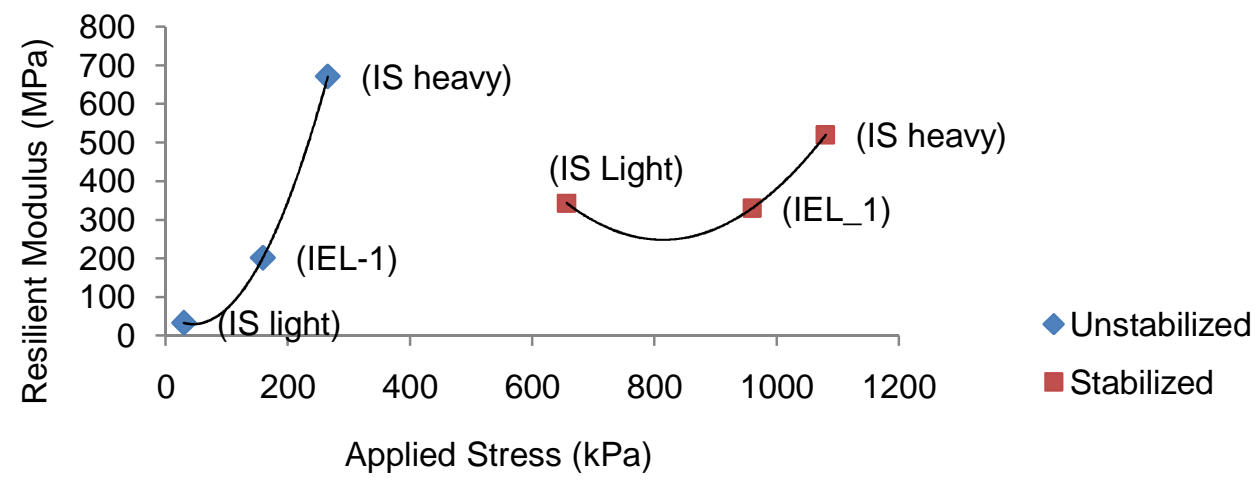

Fig. 2 Relationship Between Applied Stress and Resilient Modulus For Unstabilized and 1\% Soil Fix Stabilized Soil after 30000 Repetitions

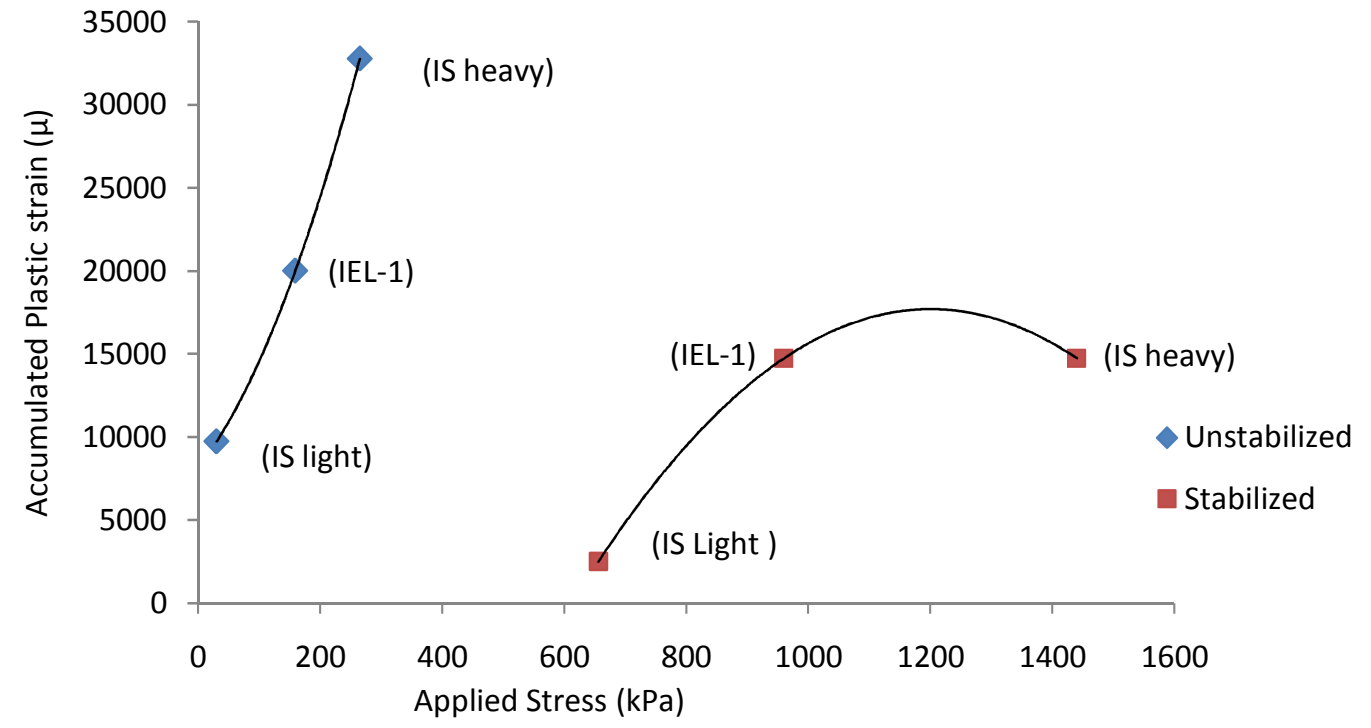

Fig. 3 Relationship between Applied Stress and Accumulated Plastic Strain for Unstabilized and $1 \%$ stabilized Soil after 30000 repetitions 


\section{CONCLUSIONS}

i) The increase in density due to increase in compaction energy is lower for stabilized soil compared to unstabilized soil.

ii) Increases of stabilizer content do not have significant influence on density and OMC increases with increase in stabilizer content.

iii) Increase in compaction energy for stabilized soil exhibit increase in UCS, resilient modulus and decrease in accumulated plastic strain.

\section{REFERENCES}

[1] Anjaneyappa, M.S. Amarnath and B.R. Srinivasmurthy "Characterisation of Polymer Stabilized Soils for Pavements" Indian Highways, Volume 40, March 2012, pp.31-40,

[2] Per Lindh "Compaction and Strength Properties of Stabilized and Unstabilized Fine Grained Tills", Doctoral Thesis, Swedish Geotechnical Institute, Linkoping (2004).

[3] Rauch, Alan F., Harman, Jacqueline S., Katz, Lynn E., and Liljestrand Howard M "Effects of Liquid Soil Stabilizers on Engineering Properties of Clays" Transportation Research Record 1787, TRB, National Research Council, Washington,DC.2003, pp.33-41.

[4] Santoni,Rosa L., Nieves, Miguel and Tingle, Jeb. "Accelerated Curing of Silty Sand Using Non Traditional Additives", Transportation Research Record, TRB, Washington. (2003).

[5] Vorobieff George, "A new Approach to Laboratory Testing of Stabilized Materials" Australian Stabilization Industry, $22^{\text {nd }}$ ARRB Conference, (2006). 